\title{
Lack of an association between -308G $>$ A polymorphism of the TNF- $\alpha$ gene and liver cirrhosis risk based on a meta-analysis
}

\author{
D. Chen ${ }^{1 *}$, J.L. Liü ${ }^{2 *}$ Y. Liu ${ }^{2}$, J. Zhu ${ }^{1}$ and S.W. Wang ${ }^{1}$ \\ ${ }^{1}$ Department of Emergency, \\ The Fourth Affiliated Hospital of China Medical University, \\ Shenyang, P.R. China \\ ${ }^{2}$ Department of Oncology, \\ The Fourth Affiliated Hospital of China Medical University, \\ Shenyang, P.R. China \\ *These authors contributed equally to this study. \\ Corresponding author: J. Zhu \\ E-mail: cmu_jiali@126.com
}

Genet. Mol. Res. 10 (4): 2765-2774 (2011)

Received January 7, 2011

Accepted July 1, 2011

Published November 8, 2011

DOI http://dx.doi.org/10.4238/2011.November.8.2

\begin{abstract}
TNF- $\alpha$ is a potential proinflammatory cytokine that plays an important role in the pathogenesis of liver cirrhosis. We investigated a possible association between TNF- $\alpha-308 \mathrm{G}>\mathrm{A}$ polymorphism and liver cirrhosis risk by conducting a meta-analysis. Publications addressing the association between TNF- $\alpha-308 \mathrm{G}>\mathrm{A}$ and liver cirrhosis risk were selected from the Pubmed and Embase databases. Data were extracted from the studies by two independent reviewers; odds ratio (OR) with a 95\% confidence interval (CI) was calculated from these data. The meta-analysis was performed by Review Manager Version 5.0.24 and STATA Version 9.2. Eleven studies were retrieved, reporting a total of 1796 liver cirrhosis cases and 2113 healthy controls. A meta-analysis of these 11 studies identified no significant association between TNF- $\alpha$ $-308 \mathrm{G}>\mathrm{A}$ polymorphism and liver cirrhosis risk in all comparisons of G vs A allele; GG vs GA + AA; GG + GA vs AA; GG vs AA; GG vs GA
\end{abstract}


$(\mathrm{OR}=1.14,95 \% \mathrm{CI}=0.85-1.55, \mathrm{P}=0.38 ; \mathrm{OR}=1.24,95 \% \mathrm{CI}=0.87-$ $1.77, \mathrm{P}=0.24 ; \mathrm{OR}=0.90,95 \% \mathrm{CI}=0.62-1.30, \mathrm{P}=0.57 ; \mathrm{OR}=1.03$, $95 \% \mathrm{CI}=0.56-1.89, \mathrm{P}=0.92 ; \mathrm{OR}=1.30,95 \% \mathrm{CI}=0.90-1.88, \mathrm{P}=0.17$; respectively). In conclusion, we found no association between TNF- $\alpha$ $-308 \mathrm{G}>\mathrm{A}$ polymorphism and liver cirrhosis risk, both in Caucasian and Asian populations.

Key words: Tumor necrosis factor; Liver cirrhosis; Meta-analysis; Gene polymorphism; Risk

\section{INTRODUCTION}

Liver fibrosis is a significant health problem with a worldwide mortality, attributable to cirrhosis and primary liver cancer, of around 1.5 million deaths per year (Lim and Kim, 2008). Cirrhosis is the last stage of fibrosis, which occurs mainly in response to viral and toxic-metabolic insults. The most common causes of fibrosis progression are chronic hepatitis $\mathrm{C}$, chronic hepatitis B, alcoholic liver disease, and nonalcoholic fatty liver disease (Poynard et al., 2003). The development of hepatic fibrosis, which leads to cirrhosis in patients, results from an inflammatory response. This process is associated with marked interpatient variation, which is difficult to predict (Bataller et al., 2003; Friedman, 2010). The wide spectrum in the rate of fibrosis progression is thought to be modulated by a combination of host genetic factors and other host variables including age, gender and alcohol intake (Bataller et al., 2003; Mallat et al., 2008). Recently, a gene variant prognostic signature for cirrhosis in patients has been developed for patients. It is known that tumor necrosis factor- $\alpha$ (TNF- $\alpha)$ is the predominant mechanism of host defense against chronic HBV/HCV infection (Thimme et al., 2003; Chuang et al., 2004). It can induce an inflammatory response that often leads to chronic liver injury (Schwabe and Brenner, 2006; Choi and Ou, 2006).

The TNF- $\alpha$ gene is located on chromosome $6 \mathrm{p} 21.3$, within the class III region of MHC (Constantini et al., 2002). TNF- $\alpha$ is a potential proinflammatory cytokine that plays an important role in the pathogenesis of liver cirrhosis (LC) (Oo et al., 2010). TNF- $\alpha$ stimulates cytokine production, enhancing expression of adhesion molecules and neutrophil activation and acts as a costimulator for T-cell activation and antibody production (Commins et al., 2010). However, it is unclear as to whether the role of TNF- $\alpha$ as a mediator of inflammation is a beneficial or deleterious one in the susceptibility to liver cirrhosis. A number of single nucleotide polymorphisms in this gene have been described (Hajeer and Hutchinson, 2000; Cuenca et al., 2001), which have been linked to higher TNF- $\alpha$ production, although conflicting results have also been reported.

Several environmental and genetic factors can play an important role in LC risk, and the potential relationship between genetic polymorphisms and this disease has been extensively investigated. Increasing evidence indicates that genetic factors can influence the natural history of chronic liver disease (Bataller et al., 2003). The capacity for cytokine production in different individuals has a major genetic component, which can be ascribed to polymorphisms within the regulatory regions of signal sequences of cytokine genes (Chan et al., 2008). TNF- $\alpha$ is the key cytokine in the inflammatory response. A number of studies have assessed the association between TNF- $\alpha$ promoter polymorphisms and LC in different populations. However, 
the results are inconsistent and inconclusive. The aim of this meta-analysis was to investigate the association between TNF- $\alpha-308 \mathrm{G}>\mathrm{A}$ polymorphism and LC risk by conducting a metaanalysis from all eligible case-control studies published to date.

\section{MATERIAL AND METHODS}

\section{Literature search strategy}

Pubmed and Embase database searches were performed to retrieve papers linking TNF- $\alpha-308 \mathrm{G}>\mathrm{A}$ polymorphism and LC risk available on line by October 2010 without language restrictions, using the following query: ["tumor necrosis factor alpha" (Mesh)] and ["polymorphism, Single Nucleotide" or "polymorphism, restriction fragment length" or "Polymorphism, Single-Stranded conformational" or "genome structural variation" or "Polymorphism, Genetic" (Mesh)] and ["Liver cirrhosis" or "Hepatic cirrhosis" (Mesh)]. The reference lists of major textbooks, review articles, and of all the included articles identified by the search were then individually searched to find other potentially eligible studies.

\section{Inclusion criteria and exclusion criteria}

To be eligible for inclusion in this meta-analysis, the following criteria were established: 1) case-control studies that addressed LC cases and healthy controls; 2) studies that evaluated the association between TNF- $\alpha-308 \mathrm{G}>\mathrm{A}$ polymorphism and LC risk; 3) all patients with clinically diagnosed LC; 4) studies that included sufficient genotype data for extraction; 5) healthy controls were in Hardy-Weinberg equilibrium (HWE). Studies were excluded when: 1) not case-control studies that evaluated the association between TNF- $\alpha-308 \mathrm{G}>\mathrm{A}$ polymorphism and LC risk; 2) case reports, letters, reviews, and editorial articles; 3) studies that were based on incomplete raw data or no usable data reported; 4) duplicate data were contained in the studies; 5) family-based design; 6) healthy controls were not in HWE.

\section{Data extraction}

Using a standardized form, data from published studies were extracted independently by two reviewers (Chen D and Liu Y) to populate the necessary information. From each of the included articles the following information was extracted: first author, year of publication, country, ethnicity, study design, source of controls, sample size, histological type, polymorphisms of gene, and evidence of HWE of controls. For conflicting evaluations, an agreement was reached following a discussion.

\section{Quality assessment of included studies}

The quality of papers was also independently assessed by two reviewers (Chen D and Liu Y) based on the STROBE quality score system (Vandenbroucke et al., 2007). Thirty items relevant to the quality appraisal were used for assessment in this meta-analysis, yielding scores ranging from 0 to 30 . Any discrepancies between the two reviewers were resolved by discussion and consultation with a third reviewer (Zhu J). 


\section{Statistical analysis}

Meta-analysis was performed using the Review Manager version 5.0.24 (provided by The Cochrane Collaboration) and STATA package version 9.2 (Stata Corporation, College Station, TX, USA). The strength of the associations between TNF- $\alpha-308 \mathrm{G}>\mathrm{A}$ polymorphism and $\mathrm{LC}$ risk was estimated by odds ratio (OR) and $95 \%$ confidence interval $(95 \% \mathrm{CI})$. The following contrasts for TNF- $\alpha-308 \mathrm{G}>\mathrm{A}$ polymorphism were evaluated: the comparison of variant alleles with wild allele ( $\mathrm{G} v s$ A allele); the comparison of each homozygote with the other combined with heterozygote (GG vs GA + AA; AA vs GG + GA), the comparison of variant homozygote with heterozygote and wild homozygote (GG vs AA; GG vs GA). Between-study heterogeneities were estimated using the Cochran Q-test (Higgins and Thompson, 2002; Zintzaras and Ioannidis, 2005). When a significant Q-test $(\mathrm{P}<0.10)$ indicated heterogeneity across studies, the random effects model was used for meta-analysis, or else the fixed effects model was used. We also quantified the effect of heterogeneity by using a recently developed measure, i.e., $\mathrm{I}^{2}=100 \% \mathrm{x}(\mathrm{Q}-\mathrm{df}) / \mathrm{Q} . I^{2}$ ranges between 0 and $100 \%$ and represents the proportion of inter-study variability that can be attributed to heterogeneity rather than chance. $I^{2}$ values of 25,50 and $75 \%$ were defined as low, moderate and high estimates, respectively. We tested whether genotype frequencies of controls were in HWE using the $\chi^{2}$ test. Subgroup analysis based on ethnicity was used to explore and explain the diversity among the results of different studies. Sensitivity analysis was mainly performed by sequential omission of individual studies. Publication bias was investigated by Begg's funnel plot, and the funnel plot asymmetry was assessed by the Egger linear regression test (Peters et al., 2006). Statistical significance was considered when the $P$ value of the Egger test was $<0.05$. All the $P$ values were two-sided. To ensure the reliability and the accuracy of the results, two reviewers (Chen D and Liu Y) populated the data in the statistic software programs independently and got the same results.

\section{RESULTS}

\section{Studies included in the meta-analysis}

The search strategy retrieved 48 potentially relevant papers. There were 11 studies (Tanaka et al., 1999; Gordon et al., 1999; Jones et al., 1999; Bahr et al., 2003; Chen et al., 2003; Fan et al., 2004; Pastor et al., 2005; Nguyen-Khac et al., 2008; Niro et al., 2009; Jiang et al., 2009; Juran et al., 2010) included in this meta-analysis and 37 studies were excluded. The flow chart of study selection is summarized in Figure 1. These 11 case-control studies selected included a total of 1796 LC cases and 2113 healthy controls. All studies were case-control studies, which evaluated the association of TNF- $\alpha-308 \mathrm{G}>\mathrm{A}$ polymorphism and LC risk. The publishing year of the included studies ranged from 1999 to 2010. All included studies used polymerase chain reaction (PCR) or PCR-restriction fragment length polymorphism (PCR-RFLP) to detect genotypes. The HWE test was performed on genotype distribution of the controls in all studies included, all of them showed to be in HWE $(\mathrm{P}>0.05)$. The baseline characteristics and methodological quality of all studies included are summarized in Table 1. The genotype distribution and risk allele frequency are summarized in Table 2. 


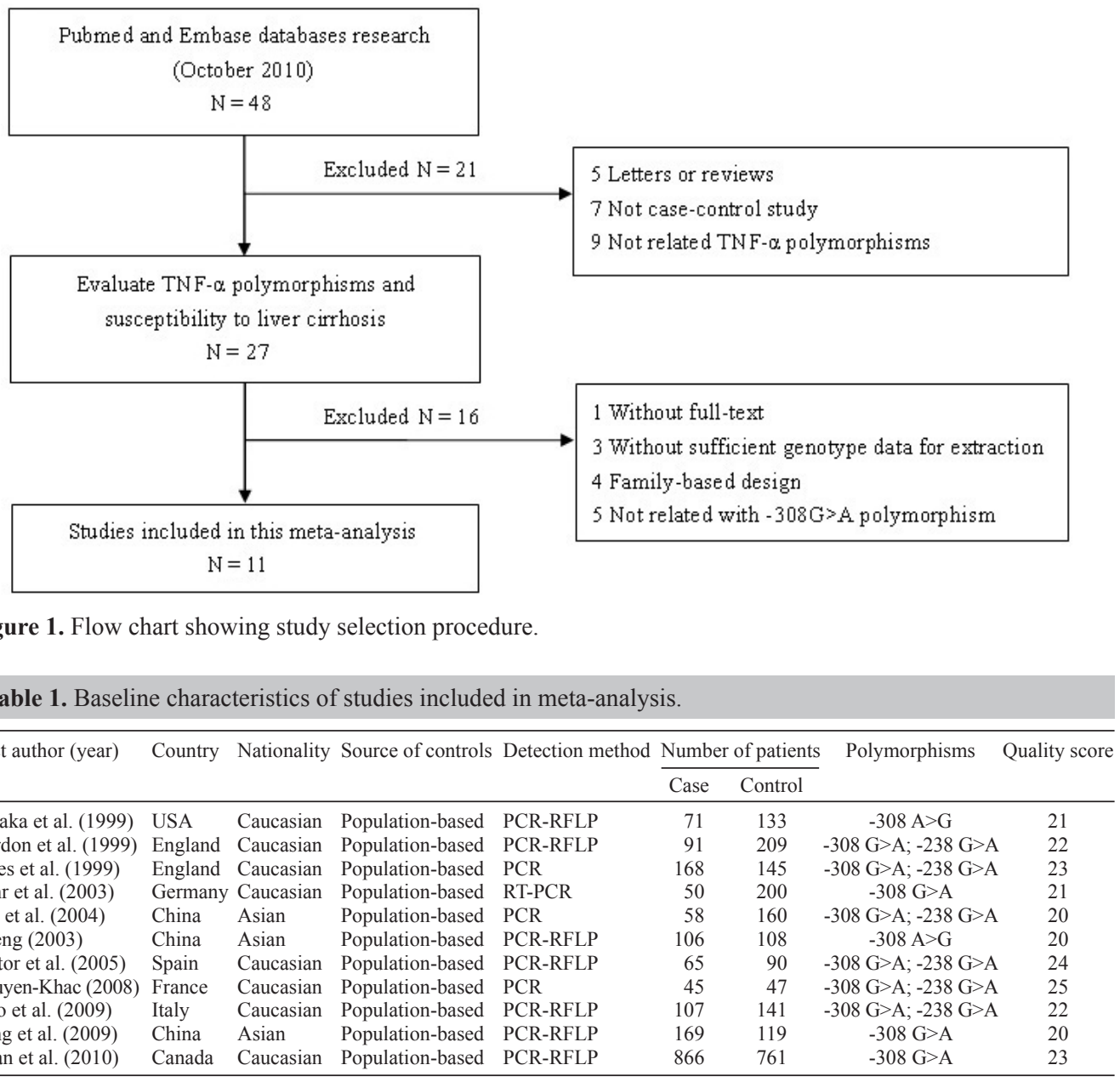

$\mathrm{PCR}=$ polymerase chain reaction; PCR-RFLP $=$ PCR-restriction fragment length polymorphism.

Table 2. The genotype distribution and risk allele frequency of all studies included.

\begin{tabular}{|c|c|c|c|c|c|c|c|c|c|c|c|c|}
\hline \multirow[t]{3}{*}{ First author (year) } & \multicolumn{10}{|c|}{ Genotype distribution } & \multicolumn{2}{|c|}{ HWE test } \\
\hline & \multicolumn{5}{|c|}{ Cases } & \multicolumn{5}{|c|}{ Controls } & \multirow[t]{2}{*}{$\chi^{2}$} & \multirow[t]{2}{*}{$P$ value } \\
\hline & No. & GG & GA & AA & A (frequency) & No. & GG & GA & AA & A (frequency) & & \\
\hline Tanaka (1999) & 71 & 56 & 14 & 1 & 0.113 & 133 & 109 & 24 & 0 & 0.090 & 1.308 & 0.253 \\
\hline Gordon (1999) & 91 & 66 & 20 & 5 & 0.165 & 209 & 122 & 78 & 9 & 0.230 & 0.626 & 0.429 \\
\hline Jones (1999) & 168 & 111 & 53 & 4 & 0.182 & 145 & 87 & 49 & 9 & 0.231 & 0.347 & 0.556 \\
\hline Bahr (2003) & 50 & 38 & 9 & 3 & 0.150 & 200 & 139 & 55 & 6 & 0.168 & 0.039 & 0.844 \\
\hline Fan $(2004)$ & 58 & 52 & 6 & 0 & 0.052 & 160 & 133 & 27 & 0 & 0.084 & 1.359 & 0.244 \\
\hline Cheng (2003) & 106 & 85 & 21 & 0 & 0.099 & 108 & 97 & 11 & 0 & 0.051 & 0.311 & 0.577 \\
\hline Pastor (2005) & 65 & 45 & 19 & 1 & 0.162 & 90 & 69 & 19 & 2 & 0.128 & 0.252 & 0.616 \\
\hline Nguyen-Khac (2008) & 45 & 26 & 13 & 6 & 0.278 & 47 & 21 & 25 & 1 & 0.287 & 4.204 & 0.040 \\
\hline Niro (2009) & 107 & 90 & 16 & 1 & 0.084 & 141 & 115 & 25 & 1 & 0.096 & 0.081 & 0.776 \\
\hline Jiang (2009) & 169 & 145 & 18 & 6 & 0.089 & 119 & 71 & 38 & 10 & 0.244 & 2.128 & 0.145 \\
\hline Juran (2010) & 866 & 597 & 235 & 34 & 0.175 & 761 & 558 & 181 & 22 & 0.148 & 2.387 & 0.122 \\
\hline
\end{tabular}

HWE $=$ Hardy-Weinberg equilibrium; $\mathrm{P}<0.05$ was considered to be statistically significant. 


\section{Main results, subgroup and sensitivity analysis}

A summary of the meta-analysis findings of the association between TNF- $\alpha-308 \mathrm{G}>\mathrm{A}$ polymorphism and LC risk is provided in Table 3. Meta-analysis of 11 studies identified no significant association between TNF- $\alpha-308 \mathrm{G}>\mathrm{A}$ polymorphism and LC risk in all comparisons of $\mathrm{G} v s$ A allele; GG $v s \mathrm{GA}+\mathrm{AA} ; \mathrm{GG}+\mathrm{GA} v s \mathrm{AA} ; \mathrm{GG} v s \mathrm{AA} ; \mathrm{GG} v s \mathrm{GA}(\mathrm{OR}=$ $1.14,95 \% \mathrm{CI}=0.85-1.55, \mathrm{P}=0.38 ; \mathrm{OR}=1.24,95 \% \mathrm{CI}=0.87-1.77, \mathrm{P}=0.24 ; \mathrm{OR}=0.90$, $95 \% \mathrm{CI}=0.62-1.30, \mathrm{P}=0.57 ; \mathrm{OR}=1.03,95 \% \mathrm{CI}=0.56-1.89, \mathrm{P}=0.92 ; \mathrm{OR}=1.30,95 \% \mathrm{CI}=$ $0.90-1.88, \mathrm{P}=0.17$, respectively). In the subgroup analysis by ethnicity, studies were divided into Caucasian and Asian populations, results also showed no significant association between TNF- $\alpha-308 \mathrm{G}>\mathrm{A}$ polymorphism and LC risk in both Caucasian and Asian populations. Sensitivity analysis was performed by sequential omission of individual studies. The significance of pooled OR in all individual analyses and subgroup analyses was not influenced excessively by omitting any single study.

\begin{tabular}{|c|c|c|c|c|c|c|}
\hline \multirow[t]{2}{*}{ Comparisons } & \multirow[t]{2}{*}{ OR } & \multirow[t]{2}{*}{$95 \% \mathrm{CI}$} & \multirow[t]{2}{*}{$\mathrm{P}$ value } & \multicolumn{2}{|c|}{ Heterogeneity } & \multirow[t]{2}{*}{ Effects model } \\
\hline & & & & $I^{2}$ & $P$ value & \\
\hline G vs A allele & 1.14 & $0.85-1.55$ & 0.38 & $75 \%$ & $<0.0001$ & Random \\
\hline Caucasian & 1.03 & $0.84-1.28$ & 0.75 & $38 \%$ & 0.13 & \\
\hline Asian & 1.43 & $0.43-4.76$ & 0.56 & $89 \%$ & 0.0001 & \\
\hline $\mathrm{GG} v s \mathrm{GA}+\mathrm{AA}$ & 1.24 & $0.87-1.77$ & 0.24 & $76 \%$ & $<0.0001$ & Random \\
\hline Caucasian & 1.35 & $0.86-2.10$ & 0.19 & $82 \%$ & $<0.00001$ & \\
\hline Asian & 0.95 & $0.57-1.60$ & 0.85 & $30 \%$ & 0.24 & \\
\hline $\mathrm{GG}+\mathrm{GA} v s \mathrm{AA}$ & 0.90 & $0.62-1.30$ & 0.57 & $35 \%$ & 0.14 & Fixed \\
\hline Caucasian & 0.77 & $0.52-1.14$ & 0.20 & $14 \%$ & 0.32 & \\
\hline Asian & 2.49 & $0.88-7.06$ & 0.09 & - & - & \\
\hline GG $v s \mathrm{AA}$ & 1.03 & $0.56-1.89$ & 0.92 & $42 \%$ & 0.09 & Random \\
\hline Caucasian & 0.81 & $0.52-1.28$ & 0.38 & $6 \%$ & 0.39 & \\
\hline Asian & 3.40 & $1.19-9.74$ & 0.02 & - & - & \\
\hline GG $v s \mathrm{GA}$ & 1.30 & $0.90-1.88$ & 0.17 & $76 \%$ & $<0.00001$ & Random \\
\hline Caucasian & 1.19 & $0.86-1.62$ & 0.29 & $58 \%$ & 0.02 & \\
\hline Asian & 1.53 & $0.38-6.12$ & 0.54 & $90 \%$ & $<0.0001$ & \\
\hline
\end{tabular}

$\mathrm{OR}=$ odds ratio; $95 \% \mathrm{CI}=95 \%$ confidence interval.

\section{Publication bias}

Publication bias of the literature was accessed by Begg's funnel plot and by the Egger test. The publication bias of the meta-analysis on the association between TNF- $\alpha-308 \mathrm{G}>\mathrm{A}$ polymorphism and LC risk was detected on the comparison of G $v s$ A allele. The graphical funnel plots of 11 studies appeared to be symmetrical. The Egger test also showed that there was no statistical significance for the evaluation of publication bias $(t=0.22, \mathrm{P}=0.831$, $95 \% \mathrm{CI}=-1.355-1.647$ ) (Figure 2).

\section{DISCUSSION}

Hepatocyte damage elicits an inflammatory response through activation of tissue macrophage Kupffer cells. These activated cells release an array of cytokines, including TNF- $\alpha$, transforming growth factor- $\beta$, platelet-derived growth factor, and other factors that act on 


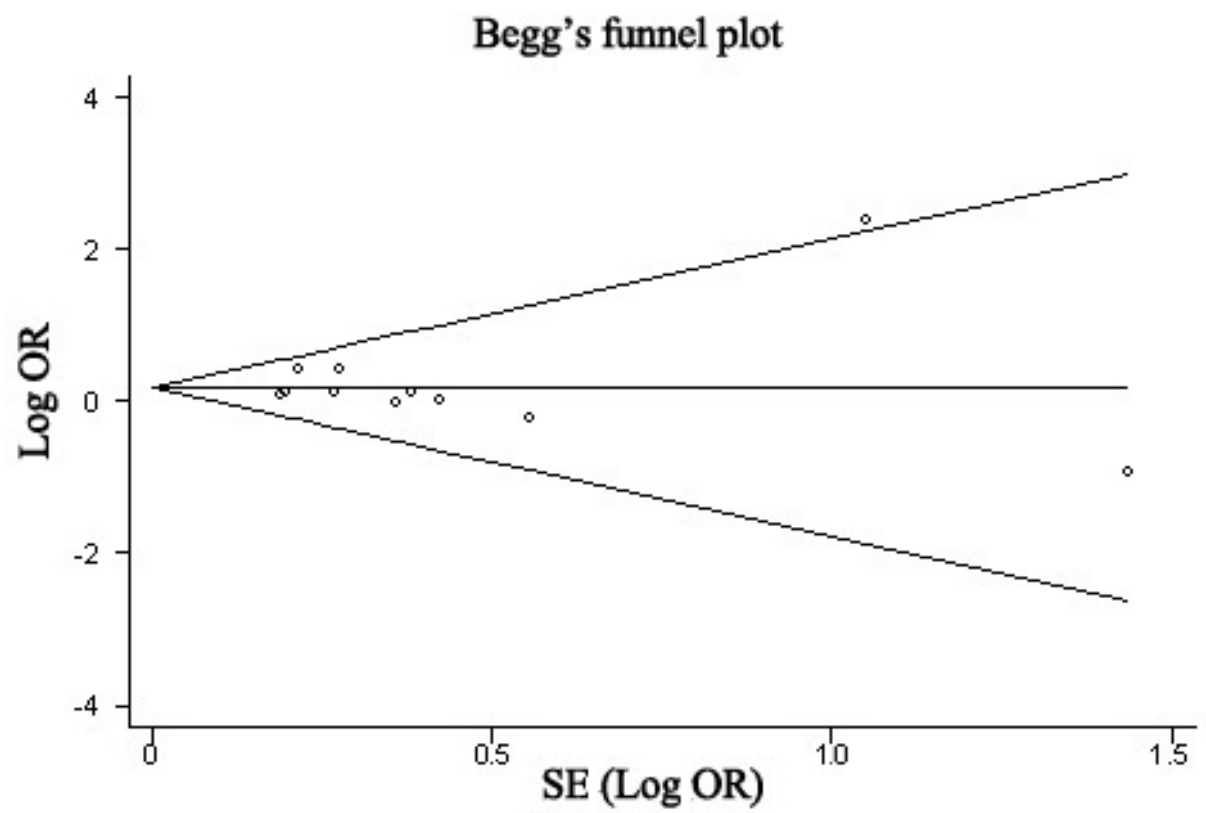

Figure 2. Begg's funnel plot and the Egger test of publication bias for the association between TNF- $\alpha-308 \mathrm{G}>\mathrm{A}$ polymorphism and $\mathrm{LC}$ risk were detected on the comparison of $\mathrm{G} v s \mathrm{C}$ allele. (Egger regression test: $t=0.22, \mathrm{P}=$ $0.831,95 \% \mathrm{CI}=-1.355-1.647)$.

hepatic stellate cells that contribute to fibrogenesis (Thimme et al., 2003; Cha and Dematteo, 2005). Among antiviral cytokines, TNF- $\alpha$ plays a pivotal role in host immune response. Circulating TNF- $\alpha$ level increases during HBV (Chuang et al., 2004; Schwabe and Brenner, 2006) and HCV infection (Elsammak et al., 2005; Falasca et al., 2006; Cua et al., 2007). An increased TNF- $\alpha$ level correlates with the severity of hepatic inflammation, fibrosis and tissue injury (Kamal et al., 2006). Persistent immune-mediated hepatic injury can initiate the process of fibrosis, cirrhosis.

As is known, genetic polymorphisms altering the level of protein expressed would be anticipated to have a substantial influence on disease activity (Tahara et al., 2009). The relationship between TNF- $\alpha-308 \mathrm{G}>\mathrm{A}$ polymorphism and LC risk has been studied in several studies, and the results are controversial. Juran et al. (2010) reported that the A allele of TNF- $\alpha$ $-308 \mathrm{G}>$ A polymorphism significantly increased the risk of liver cirrhosis, while Nguyen-Khac et al. (2008) suggested that only the A/A homozygote was associated with liver cirrhosis, and no significant association was found in other studies (Jones et al., 1999; Niro et al., 2009). During the last ten years, associations between a polymorphism involved in the structure of TNF- $\alpha$ and a functional polymorphism in the promoter region of TNF- $\alpha$ and LC have also been reported in many molecular genetic studies. This is the first systematic study of the metaanalysis of the association between TNF- $\alpha-308 \mathrm{G}>\mathrm{A}$ polymorphism and LC risk.

The capacity for cytokine production in an individual has a major genetic component, and there exist striking differences among individuals in terms of their ability to produce cytokines, which have been ascribed to single-nucleotide polymorphism (SNP) within the coding and regulatory regions of cytokine genes (Hajeer and Hutchinson, 2001). TNF- $\alpha$ expression 
is tightly controlled at the transcriptional and posttranscriptional levels. Several biallelic polymorphisms have been described within the TNF- $\alpha$ gene. Of particular interest are two biallelic SNPs at the -238 or -308 position. These SNPs result in two allelic forms. The presence of guanine defines the common variant $\mathrm{G}$ allele, and the presence of adenine defines the less common variant A allele (Wilson et al., 1992). Both SNPs have been shown to influence TNF- $\alpha$ expression. The TNF-308 G allele leads to an increased constitutive and inducible expression of TNF- $\alpha$ (Li et al., 2009). The TNF-308 G SNP has been linked with several inflammatory, autoimmune, infectious, and malignant diseases (Jeng et al., 2007).

Our meta-analysis has quantitatively assessed the association between TNF- $\alpha$ $-308 \mathrm{G}>\mathrm{A}$ polymorphism and LC risk. Finally, 11 case-control studies were included in this meta-analysis, involving 1796 cases and 2113 healthy controls. The results strongly suggested that there was no significant association between TNF- $\alpha-308 \mathrm{G}>\mathrm{A}$ polymorphism and LC risk in all comparisons of $\mathrm{G} v s$ A allele; GG $v s \mathrm{GA}+\mathrm{AA} ; \mathrm{GG}+\mathrm{GA} v s \mathrm{AA}$; GG $v s \mathrm{AA}$, and GG $v s$ GA. In the subgroup analysis by nationality, no significant association was also found between TNF- $\alpha-308 \mathrm{G}>\mathrm{A}$ polymorphism and LC risk. By sequentially removing individual studies during influence analysis, it was confirmed that all results were not materially altered by an individual study. No evidence showed publication bias in this meta-analysis for TNF- $\alpha$ $-308 \mathrm{G}>\mathrm{A}$ polymorphism. As the eligible study number was limited in the meta-analysis of TNF- $\alpha-308 \mathrm{G}>\mathrm{A}$ polymorphism, these results still need further investigation.

There were some limitations in our meta-analysis. First, because of incomplete raw data or publication limitations, some relevant studies could not be included in our analysis. Second, we were not able to address the sources of heterogeneity that existed among studies for most polymorphisms. However, we could perform subgroup stratification analysis for the limited number of published studies. Third, the lack of genotype frequency information provided by some published studies did not allow us to determine the best genetic model of inheritance to follow. Although we actively contacted the authors, they did not provide a comprehensive set of data. In addition, the small sample size available was not ideal for detecting small genetic effects. Finally, our systematic review was based on unadjusted data, as the genotype information stratified for the main confounding variables was not available in the original papers and the confounding factors addressed across the different studies were variable.

In conclusion, our meta-analysis of 11 case-control studies demonstrated that there was no association between TNF- $\alpha-308 \mathrm{G}>\mathrm{A}$ polymorphism and LC risk, both in Caucasian and Asian populations. Therefore, we stress the need for larger studies with adequate methodological quality, properly controlling for possible confounders in order to obtain valid results.

\section{ACKNOWLEDGMENTS}

We would like to thank L.L. Li (Department of Urological Surgery, the Fourth Affiliated Hospital of China Medical University) for her valuable contribution and kind revision of the manuscript.

\section{REFERENCES}

Bahr MJ, el Menuawy M, Boeker KH, Musholt PB, et al. (2003). Cytokine gene polymorphisms and the susceptibility to liver cirrhosis in patients with chronic hepatitis C. Liver Int. 23: 420-425.

Bataller R, North KE and Brenner DA (2003). Genetic polymorphisms and the progression of liver fibrosis: a critical 
appraisal. Hepatology 37: 493-503.

Cha C and Dematteo RP (2005). Molecular mechanisms in hepatocellular carcinoma development. Best Pract. Res. Clin. Gastroenterol. 19: 25-37.

Chan HL, Tse AM, Chim AM, Wong VW, et al. (2008). Association of cytokine gene polymorphisms and liver fibrosis in chronic hepatitis B. J. Gastroenterol. Hepatol. 23: 783-789.

Chen YQ, Lin JS, Tian DY and Liang KH (2003). Study on the association between the promoter polymorphism of TNF gene and cirrhosis. World J. Infect. 3: 186-190.

Choi $\mathrm{J}$ and $\mathrm{Ou} \mathrm{JH}$ (2006). Mechanisms of liver injury. III. Oxidative stress in the pathogenesis of hepatitis C virus. Am. J. Physiol. Gastrointest. Liver Physiol. 290: G847-G851.

Chuang E, Del Vecchio A, Smolinski S, Song XY, et al. (2004). Biomedicines to reduce inflammation but not viral load in chronic HCV-what's the sense? Trends Biotechnol. 22: 517-523.

Commins SP, Borish L and Steinke JW (2010). Immunologic messenger molecules: cytokines, interferons, and chemokines. J. Allergy Clin. Immunol. 125: S53-S72.

Constantini PK, Wawrzynowicz-Syczewska M, Clare M, Boron-Kaczmarska A, et al. (2002). Interleukin-1, interleukin-10 and tumour necrosis factor-alpha gene polymorphisms in hepatitis $\mathrm{C}$ virus infection: an investigation of the relationships with spontaneous viral clearance and response to alpha-interferon therapy. Liver 22: 404-412.

Cua IH, Hui JM, Bandara P, Kench JG, et al. (2007). Insulin resistance and liver injury in hepatitis C is not associated with virus-specific changes in adipocytokines. Hepatology 46: 66-73.

Cuenca J, Perez CA, Aguirre AJ, Schiattino I, et al. (2001). Genetic polymorphism at position-308 in the promoter region of the tumor necrosis factor (TNF): implications of its allelic distribution on susceptibility or resistance to diseases in the Chilean population. Biol. Res. 34: 237-241.

Elsammak M, Refai W, Elsawaf A, Abdel-Fattah I, et al. (2005). Elevated serum tumor necrosis factor alpha and ferritin may contribute to the insulin resistance found in $\mathrm{HCV}$ positive Egyptian patients. Curr. Med. Res. Opin. 21: 527-534.

Falasca K, Ucciferri C, Dalessandro M, Zingariello P, et al. (2006). Cytokine patterns correlate with liver damage in patients with chronic hepatitis B and C. Ann. Clin. Lab. Sci. 36: 144-150.

Fan LY, Zhong RQ, Tu XQ, Pfeiffer T, et al. (2004). Genetic association of tumor necrosis factor (TNF)-alpha polymorphisms with primary biliary cirrhosis and autoimmune liver diseases in a Chinese population. Zhonghua Gan Zang Bing Za Zhi 12: 160-162.

Friedman SL (2010). Evolving challenges in hepatic fibrosis. Nat. Rev. Gastroenterol. Hepatol. 7: 425-436.

Gordon MA, Oppenheim E, Camp NJ, di Giovine FS, et al. (1999). Primary biliary cirrhosis shows association with genetic polymorphism of tumour necrosis factor alpha promoter region. J. Hepatol. 31: 242-247.

Hajeer AH and Hutchinson IV (2000). TNF-alpha gene polymorphism: clinical and biological implications. Microsc. Res. Tech. 50: 216-228.

Hajeer AH and Hutchinson IV (2001). Influence of TNFalpha gene polymorphisms on TNFalpha production and disease. Hum. Immunol. 62: 1191-1199.

Higgins JP and Thompson SG (2002). Quantifying heterogeneity in a meta-analysis. Stat. Med. 21: 1539-1558.

Jeng JE, Tsai JF, Chuang LY, Ho MS, et al. (2007). Tumor necrosis factor-alpha 308.2 polymorphism is associated with advanced hepatic fibrosis and higher risk for hepatocellular carcinoma. Neoplasia 9: 987-992.

Jiang ZL, Zhang W, Zhang H and Liu YB (2009). Relationship between TNF-alpha, TGF-beta1 and IL-10 genetic polymorphisms and post- hepatitis B cirrhosis. Shi Jie Hua Ren Xiao Hua 17: 3263-3268.

Jones DE, Watt FE, Grove J, Newton JL, et al. (1999). Tumour necrosis factor-alpha promoter polymorphisms in primary biliary cirrhosis. J. Hepatol. 30: 232-236.

Juran BD, Atkinson EJ, Larson JJ, Schlicht EM, et al. (2010). Carriage of a tumor necrosis factor polymorphism amplifies the cytotoxic T-lymphocyte antigen 4 attributed risk of primary biliary cirrhosis: evidence for a gene-gene interaction. Hepatology 52: 223-229.

Kamal SM, Turner B, He Q, Rasenack J, et al. (2006). Progression of fibrosis in hepatitis C with and without schistosomiasis: correlation with serum markers of fibrosis. Hepatology 43: 771-779.

Li Y, Chang M, Abar O, Garcia V, et al. (2009). Multiple variants in toll-like receptor 4 gene modulate risk of liver fibrosis in Caucasians with chronic hepatitis C infection. J. Hepatol. 51: 750-757.

Lim YS and Kim WR (2008). The global impact of hepatic fibrosis and end-stage liver disease. Clin. Liver Dis. 12: 733 46, vii.

Mallat A, Hezode C and Lotersztajn S (2008). Environmental factors as disease accelerators during chronic hepatitis C. J. Hepatol. 48: 657-665.

Nguyen-Khac E, Houchi H, Daoust M, Dupas JL, et al. (2008). The -308 TNFalpha gene polymorphism in severe acute alcoholic hepatitis: identification of a new susceptibility marker. Alcohol. Clin. Exp. Res. 32: 822-828.

Niro GA, Poli F, Andriulli A, Bianchi I, et al. (2009). TNF-alpha polymorphisms in primary biliary cirrhosis: a northern 
and southern Italian experience. Ann. N. Y. Acad. Sci. 1173: 557-563.

Oo YH, Hubscher SG and Adams DH (2010). Autoimmune hepatitis: new paradigms in the pathogenesis, diagnosis, and management. Hepatol. Int. 4: 475-493.

Pastor IJ, Laso FJ, Romero A and Gonzalez-Sarmiento R (2005). -238 G>A polymorphism of tumor necrosis factor alpha gene (TNFA) is associated with alcoholic liver cirrhosis in alcoholic Spanish men. Alcohol. Clin. Exp. Res. 29: 1928-1931.

Peters JL, Sutton AJ, Jones DR, Abrams KR, et al. (2006). Comparison of two methods to detect publication bias in metaanalysis. JAMA 295: 676-680.

Poynard T, Mathurin P, Lai CL, Guyader D, et al. (2003). A comparison of fibrosis progression in chronic liver diseases. J. Hepatol. 38: 257-265.

Schwabe RF and Brenner DA (2006). Mechanisms of Liver Injury. I. TNF-alpha-induced liver injury: role of IKK, JNK, and ROS pathways. Am. J. Physiol. Gastrointest. Liver Physiol. 290: G583-G589.

Tahara T, Shibata T, Nakamura M, Yamashita H, et al. (2009). Effect of polymorphisms in the 3' untranslated region (3'UTR) of vascular endothelial growth factor gene on gastric cancer and peptic ulcer diseases in Japan. Mol. Carcinog. 48: 1030-1037.

Tanaka A, Quaranta S, Mattalia A, Coppel R, et al. (1999). The tumor necrosis factor-alpha promoter correlates with progression of primary biliary cirrhosis. J. Hepatol. 30: 826-829.

Thimme R, Wieland S, Steiger C, Ghrayeb J, et al. (2003). CD8 ${ }^{+}$T cells mediate viral clearance and disease pathogenesis during acute hepatitis B virus infection. J. Virol. 77: 68-76.

Vandenbroucke JP, von Elm E, Altman DG, Gotzsche PC, et al. (2007). Strengthening the Reporting of Observational Studies in Epidemiology (STROBE): explanation and elaboration. Epidemiology 18: 805-835.

Wilson AG, di Giovine FS, Blakemore AI and Duff GW (1992). Single base polymorphism in the human tumour necrosis factor alpha (TNF-alpha) gene detectable by NcoI restriction of PCR product. Hum. Mol. Genet. 1: 353.

Zintzaras E and Ioannidis JP (2005). Heterogeneity testing in meta-analysis of genome searches. Genet. Epidemiol. 28: 123-137. 